\title{
Ask the Assistant: Using Google Assistant in Classroom Reading Comprehension Activities
}

\author{
Peterus Balan Sing, Mohamad Amin Embi, Harwati Hashim
}

\begin{abstract}
Language education is ever evolving to accommodate changes brought about by time and the development and breakthroughs in the education sector in general, and to rectify or improve non-effective approaches to suit unique language learning needs that may arise. This research was carried out to investigate the use of Google Assistant to help a group of rural primary learners in Baram, Sarawak, Malaysia who struggled with reading comprehension activities. There are two main objectives outlined for this study. First, the research sought to explore the effectiveness of using new emerging technologies such as AI-enabled virtual assistants such as Google Assistant, and to determine its usefulness in language teaching and learning under the technology-assisted language learning (TALL) paradigm. The research also sought to investigate the positive impacts brought by the usage of Google Assistant in classroom practices, namely in reading comprehension activities, and to an extent other language learning process as well. It was found that Google Assistant is an effective language learning facilitator in reading comprehension activities and brought notable positive impacts in reading comprehension activities.

Index Terms-AI-enabled virtual assistant, Google Assistant, reading comprehension, technology-assisted language learning
\end{abstract}

\section{INTRODUCTION}

Like any other fields of study, language education is ever evolving to accommodate changes brought about by time and the development and improvement in the education sector in general (revised and improved theories, new methodologies and strategies, etc.). It is also to rectify or to overhaul non-effective approaches to suit language learning needs over time.

This research was undertaken to address a problem identified in a group of rural primary school learners in a district in Sarawak, Malaysia. The pupils had difficulties performing in reading comprehension activities (which is a vital part in ESL learning), whereby text length and text presentation were among chief issues identified by the learners [12][13]. Therefore, an alternative was proposed in the form of using Google Assistant in reading comprehension activities in the classroom, specifically when learners carry out mini research based on content taught in the classroom.

Peterus Balan Sing, Faculty of Education, National University of Malaysia (UKM), Bangi, Malaysia

Mohamad Amin Embi, Faculty of Education, National University of Malaysia (UKM), Bangi, Malaysia

Harwati Hashim, Faculty of Education, National University of Malaysia (UKM), Bangi, Malaysia

\section{RESEARCH OBJECTIVES}

There are two main objectives outlined for this study. First, the research sought to explore the effectiveness of using new emerging technologies such as AI-enabled virtual assistants such as Google Assistant, and to determine its usefulness in language teaching and learning.

The research also sought to investigate the positive impacts brought by the usage of Google Assistant in classroom practices, namely in reading comprehension activities, and to an extent other language learning process as well.

\section{RESEARCH QUESTIONS}

This research attempted to answer the questions:

1. How effective is Google Assistant as a language learning tool for reading comprehension?

2. Can Google Assistant be used as a tool in language teaching and learning?

\section{LITERATURE REVIEW}

\section{Artificial Intelligence}

Artificial intelligence has been defined rigorously by various proponent over the recent years, taking up different perspectives depending on field of studies concerned (computer science, ICT, etc.). However, they all take into consideration two important dimensions, which are thought process and reasoning, and behavior [1].

Some proponents thought of AI as systems that think like humans, where AI is seen as a new endeavour into making computers think, or at least imbue computers with human-thinking abilities such as making decisions, solving problems, and learning [2]. On the other hand, some thought AI as systems that act like humans [3][4]. They believed AI is more of making machines able to carry out functions that require what is equivalent to human intelligence.

AI can also be systems that think rationally, in which AI is perceived as a result of a systemic effort into creating mental capabilities (perception, reasoning, taking action) from computational models [5][6]. This is further strengthened by proponents who believe that the systems could also act rationally; Schalkoff, and Luger and Stubblefield postulated that computational processes could potentially emulate and automate intelligent behaviours [7][8]. 


\section{Virtual Assistant and Artificial Intelligence}

$\mathrm{AI}$ is seen as a more recent element in the digital virtual personal assistant technology. The early days saw the first forms of digital personal assistants such as IBM's Shoebox had the capacity to process up to 16 words and numbers in the 1960s. Then, Microsoft came up with the notable Clippy in mid-1990s - an assistant that helps users with using the Microsoft Office software. In more recent years, advancement in mobile technology enable virtual assistants to be integrated in smartphones, such as Siri by Apple Inc., Alexa by Amazon, Google Now by Google, and Cortana by Microsoft. All of them depend heavily on speech recognition technology, and also the Internet of Things, which is a form of streamlined data of various forms from virtual and physical sources that are interconnected via cloud computing.

AI-enabled virtual personal assistants perform tasks within their operational framework, such as data and task management, and while certain specific functions may vary according to different operating systems, AI-enabled virtual personal assistants carry out similar sets of functions. These functions are usually voice-enabled.

Potential Educational Applications of AI-Powered Virtual Assistants

AI-enabled virtual personal assistants, as they are, are still massively underutilised, and more functions and capabilities are developed as time progresses. They also present an untapped potential to be utilised in the education sector, as there is a genuine need to reshape teaching and learning practices to increase their efficiencies in line with the tenets of $21^{\text {st }}$ century learning [9]. The fact that most learners now are digital natives too is note-worthy, and therefore considering new technologies such as AI-enabled virtual personal assistants as educational tools is merited.

However, in rural settings, availability of technological applications like this is limited; therefore rather than presenting this technology as an aid to help learning in digital natives (which most rural learners are not), this emerging technology could be presented a way to both engage rural learners technologically, and to value-add their learning experience [10].

The use of technologies such as AI-enabled virtual personal assistants in language teaching and learning context falls under TALL, full for technology-assisted language learning. TALL is an inclusive term to flexibly describe the paradigm in which technologies are used to support teaching methodologies [11]. and it encompasses both preexisting and emergent technologies.

\section{Reading Comprehension}

Reading comprehension is a process in which readers interact with texts to make meaning. It involves two subprocesses; decoding and comprehending.

At its bare minimum, an individual develops these two sub-skills independently of one another - implication being that while highly correlated, the development of one sub-skill does not translate into the development of the other. This is where the problem begins. Pupils were able to recognise and vocalise single words satisfactorily (decoding), but when faced with the reading comprehension they showed alarmingly low performances.

This observation is similar to the one made by Oakhill and Cain [12], who observed that a number of children face problems with reading comprehension, even when they are able to perform in single-word recognition and have adequate vocabularies. They also mentioned that although greatly correlated, a substantial minority of children develops the decoding part of reading but not the comprehending, and these group of children are characterised as 'poor comprehenders'. Indicators of 'poor comprehenders' are as follows (but not limited to these):

- They make ineffective text connecting inferences.

- They cannot integrate information explicitly contained in the text to ensure cohesion between different sentences [13].

- They have difficulties in incorporating information outside of the text (exophoric information or general knowledge) with information present in the text to fill in missing details [12].

They also concluded that comprehension skills do not automatically develop once the word-recognition skills are established, but rather it depends on other set of skills and may need specific teaching.

\section{METHODOLOGY}

The research design used for this study is based from an action-reflection version of Lewin's action research model. [14].

\section{A. Population and Sample}

This study involved ten Year Four pupils (seven boys and three girls) from a school in a district in Sarawak, Malaysia. They were selected via convenience sampling. Convenience sampling was opted for this research after taking into consideration logistical and communication difficulties that would entail if the population covers neighbouring schools. A smaller sample would also allow the researcher to provide more focus on the research participants and obtaining more in-depth data from them.

All the participants are ethnic Kayans; they speak mainly Kayan and also the basic Malay. Their English proficiency ranged from slightly more than average to limited Level of exposure to out-of-class English varied; depending on home environment and the participants' own innate interest. All of them had basic exposure to using the internet in some sort doing word processing and basic internet search using web browsers; however, they were not aware of Google Assistant and its applications prior to the research.

\section{B. Research Instrumentation}

The research used interviews and observation forms to collect data for analysis. Semi-structured interviews were used to obtain research participants' responses and opinions about the use of Google Assistant in their reading comprehension activities.

Observations forms were used to note participants' behaviors throughout the research process, especially when Google Assistant was used in reading comprehension 
activities. Task sheets too were used to measure participants' progress and improvement in reading comprehension before and after Google Assistant was used in reading comprehension activities.

\section{Data Collection and Analysis}

Data analysis for this research is mainly qualitative and relied heavily on narrative analysis done on the data obtained from the participants. Thematic analysis also was done to detect emerging themes or common ideas in the data obtained via semi-structured interviews.

\section{DATA ANALYSIS}

The findings of this research were tabulated and analysed based on the number of questions attempted, number of questions answered correctly, and the time taken to complete the task given.

How effective is Google Assistant as a language learning tool?

Table I Analysis of Respondents' Work, Time Taken for Task Completion and Their Perception Towards Text Read Prior to Intervention Using Google Assistant.

\begin{tabular}{|c|c|c|c|c|}
\hline Respondent & $\begin{array}{c}\text { Questions } \\
\text { Attempted } \\
\quad(x / 5)\end{array}$ & $\begin{array}{l}\text { Questions } \\
\text { Answere } \\
\quad \text { d } \\
\text { Correctly } \\
(x / 5) \\
\end{array}$ & $\begin{array}{l}\text { Time } \\
\text { taken } \\
(\text { mins })\end{array}$ & $\begin{array}{c}\text { Perceptions } \\
\text { Towards Text } \\
\text { Read }\end{array}$ \\
\hline Student 1 & 3 & 1 & 25 & Text is too long \\
\hline Student 2 & 4 & 2 & 24 & $\begin{array}{l}\text { No pictures to } \\
\text { assist reading }\end{array}$ \\
\hline Student 3 & 3 & 1 & 28 & Text is too long \\
\hline Student 4 & 2 & 0 & 29 & $\begin{array}{l}\text { Cannot find } \\
\text { required } \\
\text { information }\end{array}$ \\
\hline Student 5 & 1 & 0 & 30 & Text is too long \\
\hline Student 6 & 2 & 0 & 30 & $\begin{array}{l}\text { Cannot find } \\
\text { required } \\
\text { information }\end{array}$ \\
\hline Student 7 & 2 & 1 & 26 & $\begin{array}{l}\text { Cannot find } \\
\text { required } \\
\text { information }\end{array}$ \\
\hline Student 8 & 2 & 0 & 30 & Text is too long \\
\hline Student 9 & 4 & 3 & 24 & Text is too long \\
\hline $\operatorname{MEAN}(M)$ & 2.1 & 0.8 & 24.6 & \\
\hline
\end{tabular}

From Table I, it can be concluded that none managed to attempt all five comprehension questions. The most questions attempted by a single respondent is four questions, and out of the four questions, only three were answered correctly. The least performing respondent only managed to attempt one question, of which was not answered correctly. The average number of questions attempted was approximately two questions $(M=2.1)$, while the average number of questions answered correctly was approximately one question $(M=0.8)$. The average time taken by respondents to complete the task ranged from 24 to 30 minutes $(M=24.6)$.

Furthermore, when queried about their opinions or perceptions of the text read, none responded positively. Most respondents believed the text used was too long, (50\%), while some cited that they cannot find the required information to answer the questions given (30\%). In short, pre-intervention data shows strong indication that usual practices of teaching and learning reading comprehension do not work well with the group of respondents for this research.

The intervention using Google Assistant was done in the next cycle. Firstly, the topic was introduced briefly to the respondents, and a blank task sheet containing spaces for the respondents to complete was distributed. Then, the respondents were given guidance on how to construct Wh-questions based a set of keywords related to a topic, and the required information to be filled in the task sheet.

The respondents obtained feedback regarding the Wh-questions they constructed, and after adjustments were made, the respondents tested their questions using Google Assistant to find out the required information to fill in the task sheet provided to them. After that, they answer a set of Wh-questions related to the topic they have researched on in similar fashion prior to the intervention. The number of tasks completed, the number of tasks completed correctly, and the time taken for respondents to complete the task given were analyzed and tabulated. A short semi-structured interview to gauge respondents' perceptions towards the use of Google Assistant as a means for comprehension too was conducted.

Table II Analysis of respondents' work, time taken for task completion and their perception towards the use of Google Assistant.

\begin{tabular}{|c|c|c|c|c|}
\hline Respondent & $\begin{array}{l}\text { Questions } \\
\text { Attempted } \\
(\mathrm{x} / 5)\end{array}$ & $\begin{array}{c}\text { Questions } \\
\text { Answered } \\
\text { Correctly } \\
(x / 5)\end{array}$ & $\begin{array}{c}\text { Time } \\
\text { Taken } \\
\text { (mins) }\end{array}$ & $\begin{array}{c}\text { Perceptions } \\
\text { Towards the } \\
\text { Tool Used }\end{array}$ \\
\hline Student 1 & 5 & 4 & 16 & $\begin{array}{l}\text { Good; easy to } \\
\text { find } \\
\text { information }\end{array}$ \\
\hline Student 2 & 5 & 5 & 15 & $\begin{array}{l}\text { Very useful; } \\
\text { information } \\
\text { (search results) } \\
\text { comes with } \\
\text { images }\end{array}$ \\
\hline Student 3 & 4 & 4 & 18 & $\begin{array}{l}\text { Easier to find } \\
\text { information }\end{array}$ \\
\hline Student 4 & 4 & 3 & 20 & $\begin{array}{l}\text { (Information) } \\
\text { more focused; } \\
\text { easier to locate } \\
\text { information }\end{array}$ \\
\hline Student 5 & 3 & 2 & 20 & $\begin{array}{l}\text { More } \\
\text { interesting way } \\
\text { of finding } \\
\text { information }\end{array}$ \\
\hline Student 6 & 4 & 4 & 16 & $\begin{array}{l}\text { Easier to find } \\
\text { relevant } \\
\text { information }\end{array}$ \\
\hline Student 7 & 5 & 4 & 16 & $\begin{array}{l}\text { Information } \\
\text { comes with } \\
\text { other } \\
\text { interesting } \\
\text { things } \\
\text { (elements) } \\
\text { such as images, } \\
\text { sounds }\end{array}$ \\
\hline Student 8 & 4 & 4 & 20 & $\begin{array}{l}\text { Time saving; } \\
\text { no need to read } \\
\text { long texts }\end{array}$ \\
\hline Student 9 & 5 & 5 & 15 & $\begin{array}{l}\text { Information } \\
\text { obtained (is) } \\
\text { more relevant }\end{array}$ \\
\hline $\operatorname{MEAN}(M)$ & 3.9 & 3.5 & 15.6 & \\
\hline
\end{tabular}


From Table II, there is a general trend of positive improvement in the terms of number of attempted tasks, and number of questions answered correctly. All respondents managed to attempt more questions than the previous exercise $(M=3.9)$, and all respondents managed to also answer more questions correctly compared to the exercise prior to the intervention $(M=3.5)$. The time recorded for each respondent to complete the tasks too improved notably, with all respondents managing to complete the task at a reduced time compared to the previous attempt $(M=15.6)$.

Respondents were mainly of the opinion that the tool used (Google Assistant) helped greatly with completing the task given, and to an extend the processing of information. A thematic analysis of responses provided by respondents when asked about their opinions and perceptions towards the use of Google Assistant as a means for comprehension showed a positive trend, with most described using Google Assistant made finding information easier (Table 4.2) compared to the previous method without it. Respondents also found that multimedia elements that came with their search result using Google Assistant interesting and helpful.

In short, it could be concluded that Google Assistant is effective to an extent as a language learning tool, specifically in assisting comprehension related tasks. Compared to normal method of reading comprehension, using Google Assistant had resulted in respondents attempting more comprehension tasks, and performed better in terms of increased number of questions answered correctly. In average, it also took less time for respondents to complete the task given. Respondents' reception towards the tool is also generally positive, with most citing ease of finding information as a common benefit or advantage when using Google Assistant to complete the task given to them.

Is Google Assistant ultimately a tool that can be used in language teaching and learning?

To consider Google Assistant to be a functional tool used in language teaching and learning, it could be considered in two perspectives; learners' performance and learners' behavioral change.

Google Assistant had evidently shown that it brought positive impacts towards learners' performance earlier on, where there were notable improvements in three parameters investigated; average number of questions attempted, average number of questions answered correctly, and the average time taken to complete the exercise given all seen remarkable improvements. Therefore, in terms of learners' performance, the use of Google Assistant could be considered a viable tool in language teaching and learning.

The same positive trend could also be seen in learners' behavioral change, whereby they have developed a more positive reception towards the use of Google Assistant in reading comprehension activities. When probed further, respondents also indicated willingness and preference to using Google Assistant as a tool for language learning activities in the future.

Therefore, it could be concluded that after considering the two perspectives, Google Assistant could potentially be a viable tool to supplement language teaching and learning processes in the classroom.

\section{DISCUSSION}

Based on the findings of this research, Google Assistant has been proven to an extent to be an effective tool based on three observable criteria; number of questions attempted, number of questions answered correctly, and time taken to complete comprehension tasks. The use of Google Assistant also has brought observable positive effects towards how respondents perceive the reading comprehension task itself. They find it more enjoyable for several reasons; ease of obtaining required information, improved presentation of information, and the element of fun and interactivity when using the tool, and this is a clear evidence of said technology's added value to the learning process [10]. The results in the present research are comparable with the findings in the study by deHaan and Johnson, in which technology assisted learning approaches coupled with strategic interaction resulted in increased learner motivation and better language performance [15].

Therefore, based on the data and observations obtained, it could be asserted that Google Assistant is indeed a viable tool to teach and learn language, specifically in assisting learners with reading comprehension tasks.

\section{CONCLUSION}

The researcher, upon completing the course of the research, has several suggestions outlined for more in-depth studies in the future. This takes into consideration that this research was an exploratory one, and therefore continuous studies must be done in order to gain more understanding and new insights.

As commonly accepted, the normal practice of reading comprehension entails reading bodies of text, from which learners are to draw pertinent information to be used in reading comprehension activities. In this research, the subject matter used was strictly factual, or deals exclusively with facts. In practice, there are more than factual texts that are used as reading materials, such as non-linear texts, texts with fictional information, and even short stories. Therefore, it would be appropriate to conduct similar studies with these different types of texts to test Google Assistant's viability in dealing with different types of text, and to study how it fares in different text usage.

Testing for reading comprehension is also multi-faceted; there are many ways through which learners' understanding of the text they read could be tested other than just answering Wh-questions in writing. Among other notable types of reading comprehension tasks are multiple-choice questions (MCQ), true/false statements, information transfer, and higher-order opinion writing. Therefore, it would be appropriate to also conduct similar studies to test how Google Assistant could assist learners in performing in the other types of assessment tools or methods. 
If thoroughly pursued, more in-depth studies could bring about several implications towards the field of language teaching and learning at various levels. At a more grassroots level, the use of Google Assistant in language classrooms will offer teachers or language instructors alternative methods of teaching in comparison to the normally practiced ones. This potentially open new possibilities in teaching methodologies, as well as development of newer teaching aids and tools that cater to different language teaching and learning needs as they arise. Learners could also be more participative in their own language learning experience as the use of AI-powered virtual assistants requires a more active participation on the part of the learners, and therefore the learning process itself gradually becomes learner-centric.

At a wider scope, results through more thorough studies may mandate the development of an AI-powered virtual assistant specifically for educational purposes, as what is available today (such as Google Assistant and many more other AI virtual assistants) were not build specifically with education in mind. More studies could also be carried out to gather enough data that is significant enough to suggest mainstreaming the use of tools like Google Assistant in the education macrosphere.

However, also considering that tools such as Google Assistant were not originally made for educational purposes, the use of said tools may also raise ethical and moral issues, mainly as to the potential harm or disadvantage it may cause to learners if used unsupervised and unregulated in the classroom.

In conclusion, based on the data gathered in this research, Google Assistant (and AI-powered virtual assistants at large) has proven to be a useful and effective tool in language teaching and learning, though were not developed specifically for educational purposes. This presents a very interesting and creative new opportunities that should be explored and studied exhaustively so that newer educational advancements based on current trends in technological developments could be made in the spirit of keeping up with Industrial Revolution 4.0 and to fulfil the requirements of 21 st century learning.

\section{REFERENCES}

[1] Russell, S. J. \& Norvig, P. (2016). Artificial intelligence: A modern approach. NJ: Prentice Hall.

[2] Haugeland, J. (1985). Artificial intelligence: The very idea. MA: MIT Press.

[3] Kurzweil, R. (1990). The age of artificial intelligent machines. MA: MIT Press.

[4] Rich, E. \& Knight, K. (1991). Artificial intelligence. NY: McGraw-Hill.

[5] Charniak, E. \& McDermott, D. (1985). Introduction to artificial intelligence. MA: Addison-Wesley.

[6] Winston, P. H. (1992). Artificial intelligence. MA: Addison-Wesley.

[7] Schalkoff, R. I. (1990). Artificial intelligence: An engineering approach. NY: McGraw-Hill.

[8] Luber, G. F. \& Stubblefield, W. A. (1993). Artificial intelligence: Structures and strategies for complex problem solving. Redwood City, CA: Benjamin/Cummings Pub. Co.

[9] Maris, S., Maris, S. A., Dungan, L., \& Slavici, T. (2018). Re-shaping education: The role of internet resources in increasing the efficiency of the educational process. BRAIN - Broad Research in Artificial Intelligence and Neuroscience. Vol 9(1), 132-137

[10] Sundeen, T. H. \& Sundeen, D. M. (2013). Instructional technology for rural schools: Access and acquisition. Rural Special Education Quarterly. Vol 32(2), 8-14.
[11] Jameel Ahmed. (2016). Technology assisted language learning is a silver bullet for enhancing language competence and performance: A case study. International Journal of Applied Linguistics \& English Literature. Vol 5(7): 118-131

[12] Oakhill, J., \& Cain, K. (2000). Children's difficulties in text comprehension: Assessing causal issues. Journal of Deaf Studies and Deaf Education. Vol 5(1), 53-58.

[13] Oakhill, J. V., Yuill, N. M., \& Parkin, A. (1986). On the nature of the difference between skilled and less-skilled comprehenders. Journal of Research in Reading. Vol 9: 80-91.

[14] Lewin, K. (1951). Field theory in social sciences. New York: Harper \& Row.

[15] deHaan, J. \& Johnson, N. H. (2012). Enhancing the scenario: Emerging technologies and experiential learning in second language instructional design. The International Journal of Learning. Vol 18(4), 322-333

Peterus Balan Sing is a student at Universiti Kebangsaan Malaysia (UKM), currently pursuing his Master of Education in Teaching English as a Second Language (TESL). He graduated with a Bachelor of Teaching also in TESL from the Institute of Teacher Education (ITE) Malaysia, Batu Lintang Campus, Sarawak in 2015. He is now teaching in Sekolah Kebangsaan Long Naah, a rural primary school in Baram, Sarawak, Malaysia. He had participated and won a silver medal in the International Invention \& Innovative Competition 2018 in Kuala Lumpur, Malaysia.

Mohamad Amin Bin Embi PhD, is a professor of technology-enhanced learning at the Faculty of Education, Universiti Kebangsaan Malaysia. He is a leading a consultant, expert and master trainer on e-Learning in Malaysia and in the Asia-Pacific region. Under the Malaysian Higher Education Leadership Academy's Training of Master Trainers Programme, he has conducted more than 200 specialized training on e-Learning, interactive lecture, e-content development, Web 2.0, OER and MOOC. He has received numerous prestigious international awards including the Open Education for Excellence Individual Educator Award 2016 and the Open Education for Excellence Open MOOC Award 2016 (from the Open Education Consortium) as well as the ISESCO Prize for Science \& Technology in 2010 (for e-Learning Technology). He has also received several national awards including the National Academic Award 2006 (Teaching Innovation), the Muslim Outstanding Award 2008 (Education), the Malaysia Achievement Award 2012 (Outstanding Achievements in Education Category), the Higher Education e-Learning Personality 2014 and the Higher Education Best e-Learning Facilitator 2014.

Harwati Bin Hashim $\mathrm{PhD}$, is a senior lecturer at the Centre for Teaching and Learning Innovations, Faculty of Education, Universiti Kebangsaan Malaysia (UKM). She is an educational technology enthusiast and an m-learning practitioner. Her areas of concentration are TESL, mobile learning, Mobile-assisted Language Learning (MALL), Technology-enhanced Language Learning (TELL), technology acceptance as well as language pedagogy and the use of technology in teaching English as a Second Language (ESL). 